\title{
Effect of Therapy on Cerebral Blood Flow Following Aneurysm Surgery
}

\author{
BRYCE WEIR, ROBERTO DELEO and DEVIDAS MENON
}

\begin{abstract}
SUMMARY: The authors report on a patient with a ruptured anterior communicating aneurysm treated surgically on the day following her subarachnoid hemorrhage $(S A H)$. Repeated measurements of cerebral blood flow ( $\mathrm{C} C \mathrm{BF}$ ) were carried out using the inhalational Xenon 133 method. Dramatic acute increases in $\mathrm{rCBF}$ occurred, coincident with clinical improvement, following mannitol, CSF drainage and dopamine. Later, further elevation to normal levels occurred following ventriculoperitoneal shunting.
\end{abstract}

RÉSUMÉ: Les auteurs rapportent l'histoire d'un patient dont l'anévrysme rupturé de la communicante antérieure fut opéréle jour suivant l'hémoragie sous-arachnoidienne. Des mesures répétées du flot cérébral (rCBF) par la méthode d'inhalation au Xenon 133 furent effectuées. Des augmentations aiguès dramatiques du rCBFfurent observées en même temps que l'amélioration clinique suivant le manitol, le drainage du LCR et la dopamine. Une élévation subséquente vers des taux normaux a suivi la dérivation ventriculo-péritonéale.

From the Divisions of Neurosurgery and Biomedical Engineering. University of Alberta. Edmonton, Alberta.

Reprint requests to: Dr. Bryce K. A. Weir. Neurosurgical Associates, Suite 520 - 8409 112th Avenue. Edmonton, Alberta. T6G IK6, Canada.

\section{INTRODUCTION}

Regional cerebral blood flow (rCBF) responses to subarachnoid hemorrhage (SAH) from ruptured aneurysms has been the object of several recent studies (Grubb et al., 1977; Ishii, 1979; Weir et al., 1978). The necessity of intracarotid administration of Xenon 133 (Xe 133) limited the applicability of this method. The atraumatic inhalation method of Obrist (Obrist et al., 1975) has permitted us to make repeated examinations on the same patient.

Recently, new therapeutic regimens have been advocated (Brown et al., 1978; Kosnik and Hunt, 1976; Pritz et al., 1978) to improve cerebral perfusion following SAH and aneurysm surgery. It has been assumed, but not demonstrated that such measures as induced arterial hypertension, hypervolemia, increased cardiac output, and intracranial hypotension would all increase rCBF.

We report on a patient in whom the beneficial effects of such therapy were documented with repeated $\mathrm{rCBF}$ measurements.

\section{CASE REPORT}

A previously well 26 year old female suddenly collapsed five hours prior to admission. She remained unconscious and upon arrival at the emergency department was unresponsive to deep pain, flaccid, intubated, but breathing spontaneously. There were basal and apical rales. Retinal hemorrhages were present in both eyes and the pupils were $2 \mathrm{~mm}$. and fixed. A CAT scan showed intraventricular and subarachnoid blood (Figure 1). Angiography demonstrated an anterior communicating artery aneurysm (Figure 2).

The day following, after mannitol, lasix and respiratory support, she improved to the point where her eyes would occasionally open and both sides moved weakly to pain. Her left pupil was normal, the right was sluggish in response to light.

She was taken to the operating room about eight hours following her SAH and the aneurysm was clipped uneventfully. The subarachnoid space was irrigated intraoperatively. A ventricular catheter was placed and a drain was left in the subarachnoid space. An ICP monitor was placed extradurally. The patient was made slightly hypervolemic and her blood loss was more than adequately replaced. Angiography carried out immediately postoperatively demonstrated satisfactory obliteration of the aneurysm and no vasospasm. A CAT scan performed at the same time showed residual intraventricular blood.

She did not rouse following the surgery and the next day remained without spontaneous movement or eye opening and was still intubated although she was breathing on her own. Blood pressure ranged from $200 / 120$ to $140 / 90$ and intracranial pressure (ICP) was around 20 to 40 (all in $\mathrm{mm} \mathrm{Hg}$ ) although the latter occasionally peaked higher. Regional cerebral blood flow (r CBF) was then measured* and various acute therapies were instituted. These are shown in figure 3 with the results of therapy. The use of mannitol increased mean rCBF by $28 \%$. CSF drainage and dopamine resulted in a further increase to $38 \%$ above baseline (Table 1). In this period of just under two hours the patient became much lighter and started to open her eyes to command and move her limbs to request. In addition, the sluggish response of the left pupil became normal.

*Inhalational Xenon ${ }^{133}$ method using "Inhamatic 17" manufactured by Medimatic, Division of M.I.D. Inc. 17925 Sky Park Circle, Suite E, Irvine, Calif. 92714 
TABLE 1

\begin{tabular}{cccccc}
\hline SAH Day & Flow & Mean Fg & $\begin{array}{c}\text { \% Increase } \\
\text { Mean Flow }\end{array}$ & $\begin{array}{c}\% \text { Ischemic } \\
\text { Regions }\end{array}$ & $\begin{array}{c}\% \text { Severely } \\
\text { Ischemic } \\
\text { Regions }\end{array}$ \\
\hline 2 & 1 & 32 & - & $82 \%$ & $27 \%$ \\
& 2 & 41 & $+28 \%$ & $46 \%$ & $18 \%$ \\
21 & 3 & 44 & $+38 \%$ & $33 \%$ & $25 \%$ \\
91 & 4 & 44 & $+38 \%$ & $46 \%$ & $0 \%$ \\
& 5 & 63 & $+97 \%$ & $0 \%$ & $0 \%$ \\
\hline
\end{tabular}

Flow studies down using inhalation of Xenon 133. A one-minute of inhalation followed by ten minutes of clearance yielded flows. Blood flow (Fg) of the "fast" component (grey matter) is given in $\mathrm{ml}$ blood $/ 100 \mathrm{gm}$ tissue $/ \mathrm{min}$. A sixteen channel detector system was used. $\mathrm{A}$ ischemic region was defined as $\mathrm{Fg}<35$, a severely ischemic region as $\mathrm{Fg}<25$.

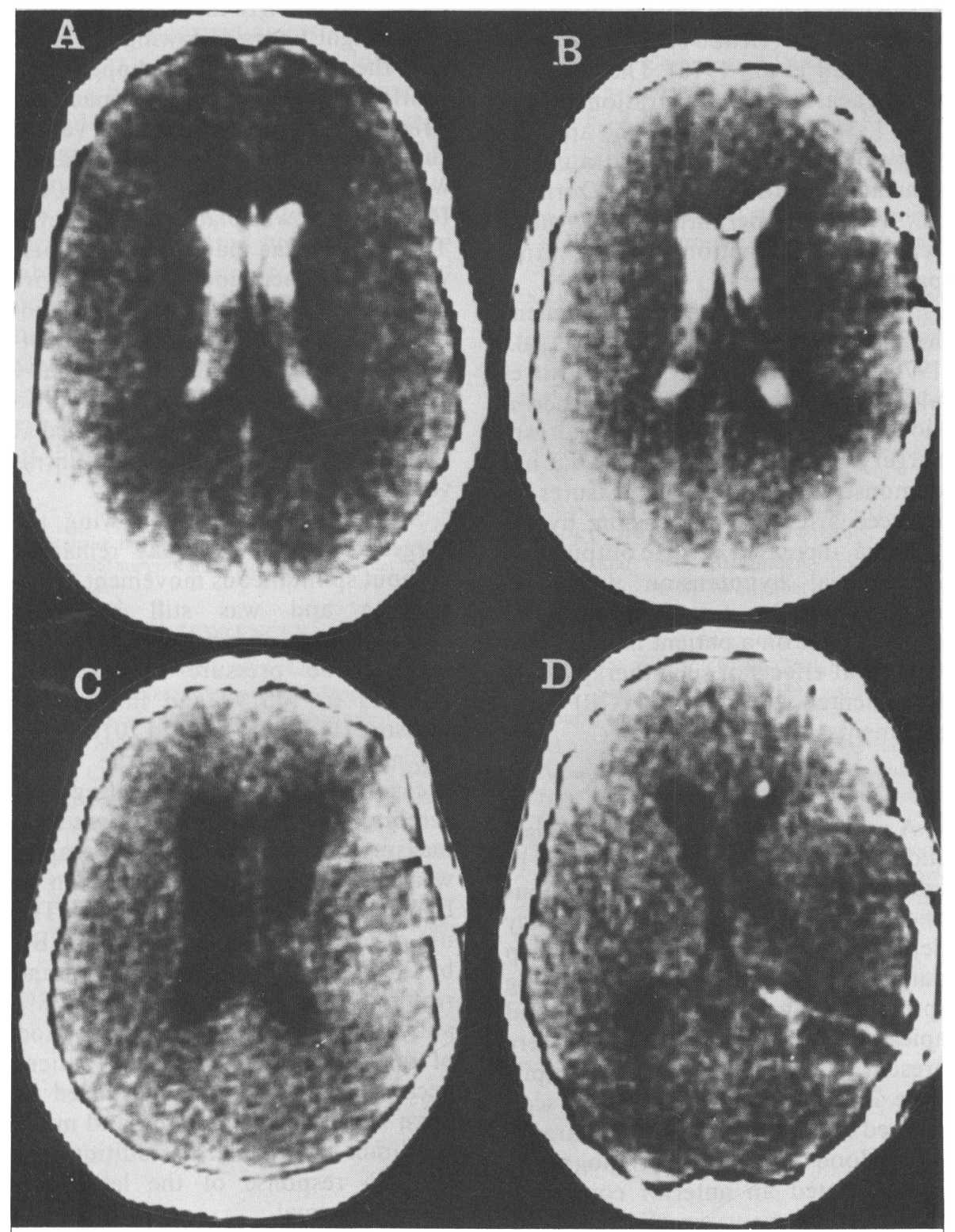

Figure 1 - A. CAT scan SAH day 0. B. CAT scan SAH day 1 , post-operative day $0 . \quad$ C. CAT scan SAH day 21 , post-operative day 20. D. CAT scan SAH day 29, postoperative (clipping) day 28 , post-operative (V-P shunt) day 7.
Her catheters, ICP monitor and endotracheal tubes were all removed by the third post-operative day. Her ICP remained between 5 and $10 \mathrm{~mm}$ $\mathrm{Hg}$ subsequent to the rCBF measurements. Intermittent CSF drainage and mild hyperventilation were employed. She was disoriented, incontinent and showed a paucity of spontaneous movement with her left limbs during this time.

On the tenth day following SAH she became less responsive and developed increased weakness of her left side and right leg. CAT scan demonstrated a lucent area in the region of the internal capsule on the right. This diminished in subsequent scans. After three days she started to improve again.

Her repeated CAT scans showed no change in ventricular size until the 16 th day post-SAH. Her neurologic improvement had plateaued and she complained of increasing headache. By the 21 st day post-SAH even further enlargement in ventricular size was present. The next day rCBF was identical to what it had been on the day following surgery after the specific therapies. A ventriculoperitoneal shunt was carried out uneventfully on the 22nd day post-SAH.

Her headache improved and she became progressively brighter, fed herself, but was not entirely appropriate or walking on her own. A CAT scan showed normal size ventricles. She was transferred to a rehabilitation institution on the 48th post-SAH day (47th day post-clipping and 25th day post-VP shunting).

A follow up blood flow study was carried out on the 91st day post-SAH. At that time she was fully oriented with no weakness or demonstrable psychological change. Her mean rCBF was 63 $\mathrm{ml} / 100 \mathrm{gm} / \mathrm{min}$. or $97 \%$ higher than the initial post-operative level.

\section{DISCUSSION}

Given this patient's prolonged initial unconsciousness, the large volume of intraventricular and subarachnoid blood, and her poor grade on initial assessment, her final outcome was gratifying.

Early surgery prevents rebleeding and permits the more vigorous use of hypertension and hypervolemia than 
might be judiciously employed in the presence of an unclipped, recently ruptured aneurysm. With intraoperative ventricular drainage, and the employment of mannitol and lasix, dissection of the aneurysm was not difficult.

Clinical improvement in the neurologic status of patients in the postoperative period following aneurysm surgery has been obtained with hypertension, intravenous fluids and transfusion (Kosnik and Hunt, 1976), albumin, transfusion, digitalization, intravenous fluids (Pritz et al., 1978) and dopamine-induced hypertension, mannitol and large volumes of intravenous fluids (Brown et al., 1978). It has been assumed that this treatment improves cerebral perfusion by increasing cerebral blood flow and reducing intracranial pressure. Measurements of cerebral blood flow in such cases were not carried out.

The deterioration on the 10th day post-SAH with a lucent lesion developing in the CAT scan was probably due to cerebral vasospasm.

This case also illustrates the association of post-SAH hydrocephalus with low mean $\mathrm{rCBF}$ levels and failure to improve clinically. Successful shunting permitted a return of rCBF to the normal range.

The management of these severely ill patients necessitates the close monitoring of blood and intracranial pressure, blood gases and electrolytes, angiographic vessel caliber and ventricular size. The ability to measure cerebral blood flow in an atraumatic and riskfree fashion is a further advance.

\section{ACKNOWLEDGEMENTS}

This work was supported by a grant from the Medical Services Research Foundation (Alberta) and Special Services Fund, University of Alberta Hospital.

\section{REFERENCES}

BROWN, F.D., HANLON, K., MULLAN, S. (1978). Treatment of aneurysmal hemiplegia with dopamine and mannitol. J. Neurosurg. 49: 525-529.

GRUBB, R.L., RAICHLE, M.E., EICHLING, J.O. (1977). Effect of subarachnoid hemorrhage on cerebral blood volume, blood flow and oxygen utilization in humans. J. Neurosurg. 46: 446-453.

ISHII, R. (1979). Regional cerebral blood flow in patients with ruptured intracranial aneurysms. J. Neurosurg. 50: 587-594.

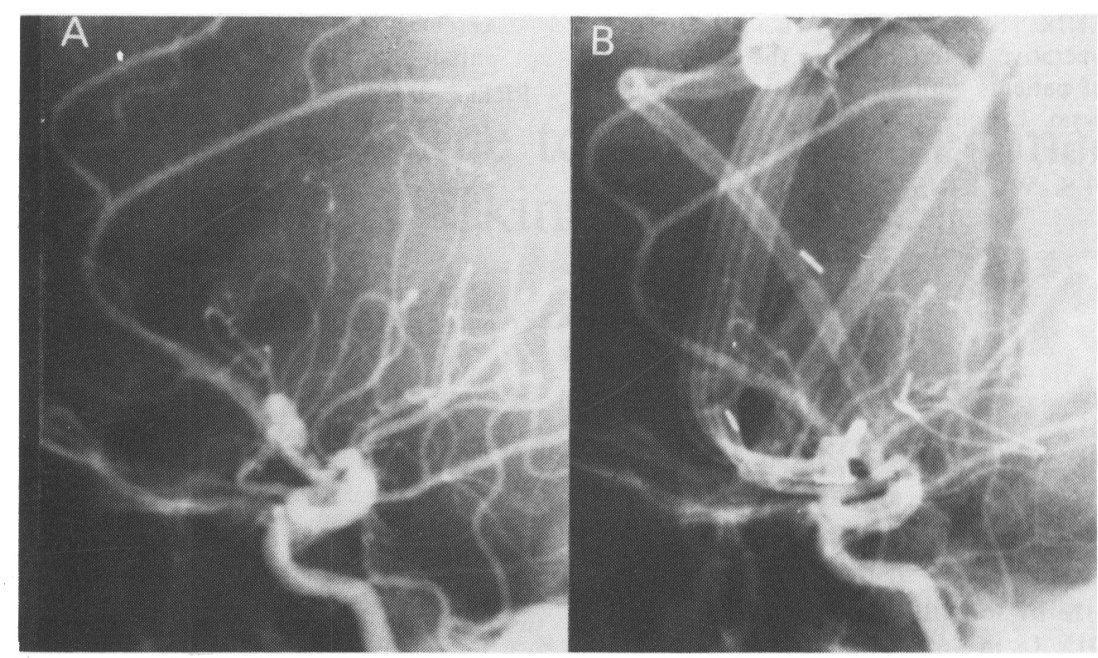

Figure 2 - A. Pre-operative lateral angiogram showing anterior communicating artery aneurysm. B. Post-operative lateral angiogram showing successful clipping with no spasm or shifts. The subarachnoid and intra-ventricular drains, and extradural pressure monitor are seen.

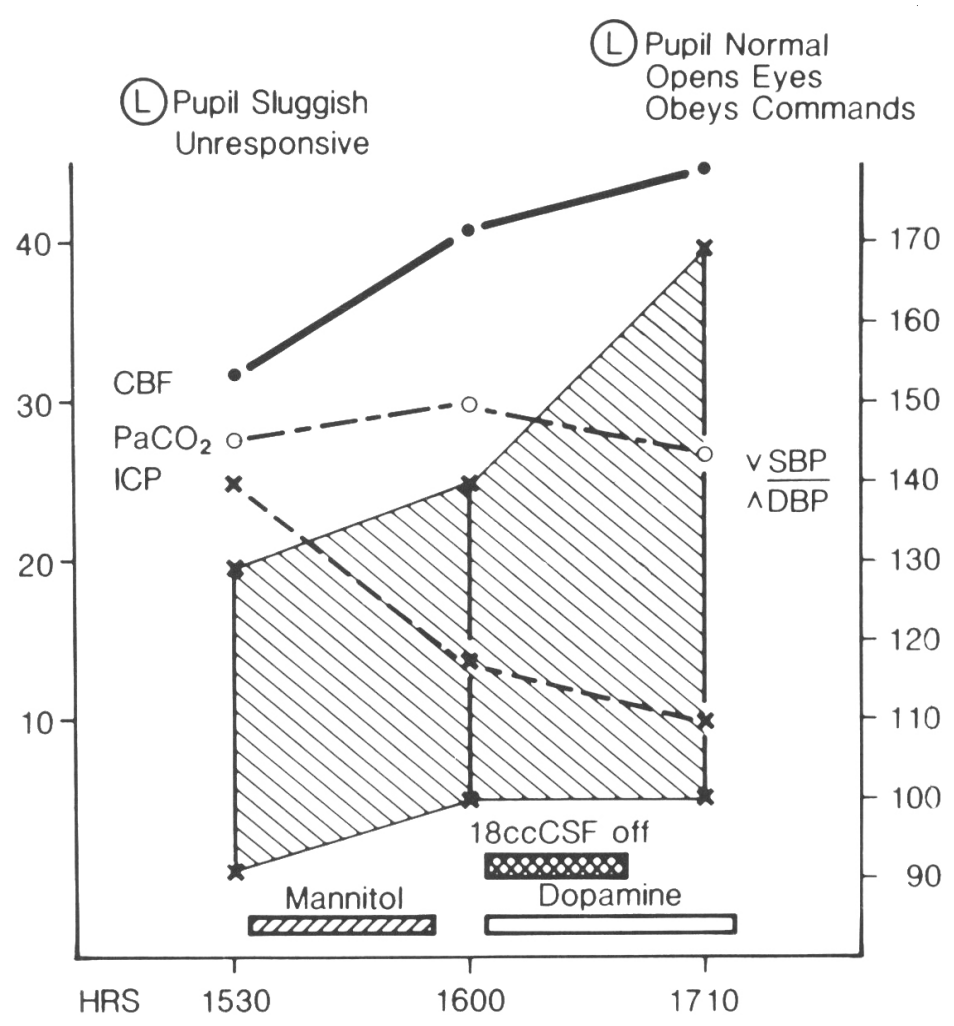

Figure 3-Mean rCBF responses to mannitol ( $250 \mathrm{cc}$ of $20 \%$ solution), removal of $18 \mathrm{cc}$ of CSF from ventricular drain and dopamine $(200 \mathrm{mgm}$ in $500 \mathrm{cc} \mathrm{D} 5 \mathrm{~W}-50 \mathrm{cc}$ of solution given over 70 minutes). Hemoglobin was $14.5 \mathrm{G} / \mathrm{DL}$. Serum osmolalities were 297, 304 and $312 \mathrm{mosm} / \mathrm{L}$. Head was elevated $30^{\circ}$. Heart rate at start of CBF studies was 86 beats per minute, at subsequent flows it was 94 and 130 . Respiratory rate was steady at $12 /$ minutes. Temperature was constant at $37.4^{\circ} \mathrm{C} . \mathrm{SBP}=$ systolic blood pressure; DBP $=$ diastolic blood pressure $; \mathrm{CBF}=$ mean regional cerebral blood flow; $\mathrm{PaCO}_{2}=$ arterial pressure $\mathrm{CO}_{2} ; \mathrm{ICP}=$ extradural intra-cranial pressure, all in $\mathrm{mm} \mathrm{Hg}$. Shaded area indicates region between systolic and diastolic blood pressures. The left hand scale indicates $\mathrm{mm} \mathrm{Hg}$ for the ICP and $\mathrm{PaCO}_{2}$, and $\mathrm{ml} / 100 \mathrm{gm} / \mathrm{min}$ for the CBF. The right hand scale indicates $\mathrm{mm} \mathrm{Hg}$ for SBP and DBP. 
KOSNIK, E.J., HUNT, W.E. (1976). Postoperative hypertension in the management of patients with intracranial arterial aneurysm. J. Neurosurg. 45: 148-154.

OBRIST, W.D., THOMPSON, H.K., WANG, H.S., WILKINSON, W.E. (1975). Regional cerebral blood flow estimated by 133 Xenon inhalation. Stroke 6: 245-255.

PRITZ, M.B., GIANOTTA, S.L., KINDT, G.W. (1978). Treatment of patients with neurological deficits associated with cerebral vasospasm by intravascular volume expan- sion. Neurosurgery 3: 364-368.

WEIR, B., MENON, D., OVERTON, T. (1978). Regional cerebral blood flow in patients with aneurysms: Estimation by Xenon 133 inhalation. Can. J. Neurol. Sci. 5: 301-305. 